Revista Iberoamericana, Vol. LXXV, Núm. 227, Abril-Junio 2009, 399-415

\title{
LA GEOGRAFÍA COMO DESTINO: JUAN BAUTISTA ALBERDI Y LA “MONSTRUOSIDAD” BRASILEÑA
}

\author{
POR \\ BETINA GonZÁLEZ \\ University of Pittsburgh
}

It proved on inquiry, that after the interest of Dr. Francia faded away, Paraguay had dropped clean out of general vision. Many, indeed, were uncertain whether it formed part of North or of SouthAmerica; and it is, I need hardly say, impossible to take any interest about the fortunes of a race whose habitat is unknown. $\quad$ Sir Richard F. Burton (1870)

El África es el doble más grande que Brasil, y su territorio entero no vale la isla de Gran Bretaña, que lo representa en la $130^{a}$ parte. No es la extensión, es la condición del suelo lo que importa considerar. Una cuestión geográfica como es ésta, no se comprenderá jamás si no se estudia con un mapa a la vista.

Juan Bautista Alberdi (1865)

\section{La Guerra del Paraguay y el destino de Sudamérica}

Los epígrafes que encabezan este trabajo tienen un elemento central en común: puestos a pensar la Guerra del Paraguay, tanto Burton como Alberdi inevitablemente comienzan por una lección de geografía. La lección incumbe a americanos y europeos, auditorios que los textos construyen desde el centro mismo de las metrópolis del Viejo Continente. Burton escribe desde Londres, luego de meses de viaje por los campos de batalla de una guerra, a la que califica como "the most remarkable campaign fought during the present century” (Burton 1). Por su parte, Alberdi escribe estos folletos en París entre 1865 y 1866, ${ }^{1}$ durante el ostracismo

1 "Las disensiones de las Repúblicas del Plata y las maquinaciones del Brasil” fue publicado en mayo de 1865 y "Los intereses argentinos en la guerra del Paraguay" en julio del mismo año, mientras que "Crisis permanente de las Repúblicas del Plata" data de febrero de 1866. Fueron reeditados en forma de libro por el propio Alberdi en 1869, edición en la que se incluía como apéndice el "Texto 
al que lo condena el gobierno argentino. Sus textos tienen el propósito declarado de acabar con la fuerte discusión que la guerra genera en el Plata y de influir tanto sobre la neutralidad del gobierno de Bartolomé Mitre en Argentina (que pronto se convertiría en participación activa del lado brasileño) como sobre la indiferencia europea (La Guerra del Paraguay 21).

Hasta aquí, las coincidencias. Burton no oculta que sus simpatías están con Brasil, a quien percibe abocado a una misión fundamental: abrir el sistema fluvial del "Mississipi del Sur”, es decir, el sistema constituido por los ríos Paraná, Paraguay y el Plata (Letters... X). Por su parte, Alberdi sostiene una única tesis a lo largo de estos ensayos: la anomalía, el crimen de esta guerra se debe a una anomalía mayor, geográfica, la "monstruosidad" de Brasil en el mapa sudamericano. ${ }^{2}$

La lección de geografía, sin embargo, cobra rutas diferentes. Burton, tal como reconoce en su Prefacio, busca iluminar, ilustrar y corregir las pobres nociones de "geografía popular" del público inglés sobre un continente que nunca deja de ser "Nuevo". Para ello, la analogía se torna operación fundamental, como lo evidencia la comparación de los deltas del Mississippi y el Plata. Paradójicamente, puesto a ubicar Paraguay en el mapa, Burton no puede dejar de diferenciar pero tampoco de igualar América del Norte y América del Sur. Es que para el inglés no se trata de traducir América a Europa sino de empezar a distinguir unidades en el cuerpo mismo del continente. Se trata de proveer otro tipo de vista sobre la naturaleza americana. De ahí la importancia del mapa: es necesario ir más allá del accidente geográfico, hacer visible al Paraguay como unidad política, recorte puntual en la naturaleza sin pausa de la América previa, que ésta-la primera "guerra de naciones" sudamericana- pone en cuestión, quizás, por primera vez.

El discurso geográfico de Alberdi también opta por esta "vista aérea" que la guerra parece exigir para ser ententida, pero va mucho más allá de la analogía ilustrativa. No es explicar ni ilustrar su intención sino trastocar, extrapolar, en definitiva, poner en movimiento el mapa de Sudamérica. En ese movimiento, Alberdi construye algo más que la defensa de Paraguay: a partir de la geografía, produce una teoría sobre el futuro, incluso sobre el destino mismo de Sudamérica. En esta teoría, las nociones de Armonía y Progreso son parte de un discurso geográfico que se articula directamente con la noción de raza. Así, Alberdi no sólo provee una teoría sobre la Guerra del Paraguay sino que se embarca él mismo en una guerra simbólica, centrada, principalmente, en los mapas. Comparar mapas equivale, en

y comentario del tratado secreto de la Triple Alianza contra el Paraguay”. Desde entonces, el libro tuvo muchas reediciones con diversos títulos. En este trabajo utilizo la edición de 2001 de Editorial Intercontinental que lo titula La Guerra del Paraguay.

2 Curiosamente, sus imágenes no difieren tanto de las de Burton: también el mito de la apertura de los ríos, el mito que equipara Comunicación y Progreso -tan caro a la élite argentina del siglo XIXcobrará un papel fundamental en su argumento, como se verá más adelante. 
este caso, a manipularlos, redibujarlos y proyectarlos hacia el futuro "ideal” del subcontinente. De esta operación proyectiva, Brasil emergerá como el principal elemento disruptivo, anómalo, monstruoso. La imbricación en el discurso geográfico deAlberdi de las nociones de "raza” y “destino" construye un imaginario que, si bien contiene elementos similares a los mitos fundacionales de la nación argentina, ${ }^{3}$ los reescribe -en el contexto de Sudamérica-con signos llamativamente diferentes. El "monstruo brasileño" es uno de los productos de este discurso geográfico-mesiánico y agita tanto los viejos fantasmas de la colonia como los fetiches de la modernidad. Exponer e interrogar el funcionamiento de ese discurso, analizar su cartografía y su política proyectivas, es el objetivo principal de este trabajo.

\section{MAGIA GEOGRÁFICA}

Más de cincuenta años antes de esta guerra, Alexander von Humboldt -reconocido por los mismos geógrafos como el padre fundador de su disciplinahabía equipado a la élite americana con una imagen de América como punto de partida; una América vacía desde la que las élites podían, cómodamente, empezar a “hacer patria”. Tal como lo señala Marie Louise Pratt, esta reinvención de América como Naturaleza otorgaba a las élites criollas un sustrato conveniente desde donde pensarse a sí mismas en relación tanto con Europa como con la masa ambigua -el pueblo americano- que imaginaban representar (Imperial Eyes).

La Guerra del Paraguay altera ese paisaje como quizás ningún otro acontecimiento del siglo. Subyace a estos textos de Alberdi que para comprender la guerra es necesario pensar en unidades mayores que la nación -pensar, por ejemplo, en Sudamérica como un cuerpo orgánico-; pero también es necesario generar diferencias allí donde el ojo extranjero sólo ve las analogías geofísicas o, peor aún, el mapa homogéneo del viejo imperio. La geografía de Humboldt que analiza Pratt -una geografía del asombro y la belleza- ya no es sustrato para esta vista. La tríada que presentara el alemán como emblema de Sudamérica -los Andes, la pampa, la selva-provee una ilusión de continuidad que la guerra destruye. En sintonía con el desarrollo mismo de la geografía en tanto campo científico, Alberdi está pensando Sudamérica en otra clave, la de una geografía preocupada no sólo por el paisaje y sus accidentes, sino por la relación del mismo con el hombre y sus instituciones. Tal geografía también podría reclamar su relación filial con Humboldt, pero con el Humboldt de Ensayo político sobre el Reino de la Nueva España (1808). En este texto, donde Humboldt va más allá de la idea de América como Naturaleza y se interesa por

\footnotetext{
3 Por ejemplo, la "teoría del vacío”, que supone a Argentina (o, por extensión, a América) como territorio a poblar. Para un análisis de esta cuestión del territorio “vacío”, ver Montaldo, 1999.
} 
el hombre americano, los problemas de la administración española y el grado de evolución del Nuevo Continente, la noción raza se torna fundamental. ${ }^{4}$

A partir de este paradigma preexistente, Alberdi puede articular un discurso geográfico de números y estadísticas, que propone una vista panorámica de Sudamérica en tanto territorio grillado y divido en zonas y razas. Es este paradigma el que le permite comparar a Brasil con África y a ésta con Inglaterra. Se trata de un discurso geográfico en el que importan las dimensiones y superficies, que reduce las opacidades del paisaje a un lenguaje nuevo, capaz de transmutar continentes enteros. Ese lenguaje provee a Alberdi de una mirada nueva, la que le permitirá explicar la anomalía de la guerra y resolver su misterio con sólo mirar el planisferio, es decir, "con un mapa a la vista".

Es que la Guerra del Paraguay mueve al mapa sudamericano y no a la inversa. Desde el Prefacio, Alberdi enuncia su tesis con claridad: la guerra de la Triple Alianza no es una guerra, sino una revolución radical del mapa:

Bajo las apariencias de una empresa militar, se está operando una revolución profunda y radical en las condiciones de existencia de esos países: en el orden social, por las reformas de sus códigos civiles; en el orden económico [...] por el cambio reaccionario del sistema de navegación fluvial; en el orden político, allí subordinado a la conformación y límites geográficos, por el cambio del mapa de América en la parte que les concierne, o lo que es lo mismo, en su equilibrio político. (Alberdi, 25)

Esta guerra que revoluciona Sudamérica no es otra cosa que el retorno de la colonia: Brasil es para Alberdi una monstruosidad, ${ }^{5}$ un anacronismo, un imperio inferior que tiene como objetivo principal restaurar la monarquía borbónica. En esta visión panorámica del mapa de Sudamérica, Brasil es conceptualizado como tres veces extranjero, "en raza, idioma y suelo" (55). Su ajenidad es construida a partir de la mirada al subcontinente, como si del suelo mismo brasileño emanara su "excepcionalidad” lingüística o racial. De ahí el eufemismo que lo define como "lo

4 La imbricación de las nociones de Raza y Geografía tiene también otras “paternidades” más allá de la obra de Humboldt, como lo demuestran, por ejemplo las conferencias que dictara Kant sobre Geografía física entre 1756 y 1796 (véase The Nature of Geography 38).

5 Es interesante que Alberdi parece estar pensando desde el tablero geográfico una preocupación no del todo ajena a los mismos intelectuales brasileños de la época. Claro que en un contexto absolutamente diferente. La obsesión por la “monstruosidad” brasileña ligada a la mezcla de razas puede rastrearse, por ejemplo, en textos fundacionales como Os Sertoes, de Euclides da Cunha y en otros textos del siglo. Como señalan Lund y McNee, es posible rastrear esta obsesión por la idea de "monstruosidad" nacional incluso en producciones culturales más actuales, desde obras como Casa-grande e senzala de Gilberto Freyre hasta películas como la de Sergio Bianchi, Cronicamente inviável (Gilberto Freyre... 7-34). 
menos feliz de Sud América” (55). Pintar a Brasil como la excepción en el (de otro modo) "armónico" mapa de las repúblicas "hispanas" es uno de los puntos centrales de la argumentación de Alberdi. Pero su retórica no está exenta de contradicciones, pues simultáneamente le da a Brasil estatus de potencia imperial. "Después de la cuestión de México no ha ocurrido en Sudamérica cuestión que haya hecho más ruido en Europa que la de Paraguay” (25) señala desde el comienzo, haciendo evidente que los ojos europeos planean sobre sus escritos y modelan sus analogías.

La mención a México no es casual, pues, más adelante, la tesis de Alberdi buscará equiparar Brasil a Francia, dibujarlo como extranjero y a la vez, como imperio colonialista en busca de nuevas tierras para la decadente dinastía de Portugal. Movimiento peligroso, pues acerca a Brasil demasiado al mapa europeo, imagen del polo civilizatorio del siglo. Justamente, de eso se trata: de dibujar y desdibujar el planisferio, de modo que la guerra acerque o aleje a Europa del escenario de las naciones sudamericanas.

A lo largo de estos ensayos Alberdi dibuja, borra y vuelve a dibujar el mapa del mundo de acuerdo a las nociones de Progreso y Civilización del siglo. Escritor extranjero en el centro mismo del mundo civilizado no puede más que forzar los límites del continente americano para dibujarlo cercano a ese centro en un diseño a veces contradictorio, a veces delirante del mapa mundial. La guerra se vuelve, entonces, instrumento de diseño y revela la existencia de dos mapas: uno simbólico y otro literal.

El "mapa literal” comprende, en este caso, tanto el viejo mapa de las colonias españolas y portuguesas, como aquel -contemporáneo al momento de escritura de Alberdi- de las naciones y sus fronteras en permanete fluctuación o discusión. Lo que se pierde en el camino entre estos mapas es el territorio "real" americano: jamás se referirá Alberdi a la cuestión del problema limítrofe de estas naciones con la minuciosidad de Burton o de Thompson ${ }^{6}$ o entrarán a en sus textos la densidad de la selva, el contorno de los ríos, la especificidad de la naturaleza que encontramos en los textos románticos o en los de los viajeros ingleses. En su contabilidad geográfica, la naturaleza se ha vuelto línea, abstracción, estadística. Sólo volverá a entrar en su discurso en el final, gracias a la reescritura de dos mitos: el de América como Paraíso y el del Progreso.

El primero y más importante de los mapas literales que redibuja Alberdi es el de la colonia española. Detrás del mapa de las repúblicas americanas alienta la sombra de la administración virreinal. Alberdi denuncia más claramente que los cronistas ingleses las pretensiones de anexión del gobierno de Buenos Aires del

\footnotetext{
6 George Thompson, ingeniero inglés al servicio de los ferrocarriles paraguayos, es uno de los primeros cronistas de esta guerra. Su libro es intertexto obligado de crónicas posteriores, incluso de las cartas del mismo Richard Burton (véase The War in Paraguay).
} 
territorio paraguayo desde el momento mismo de la Emancipación, pretensión calcada sobre el mapa del Virreinato del Río de la Plata. Paradójicamente, este mapa construye a Paraguay como Estado de resistencia permanente frente a la voluntad expansionista de sus vecinos pero a la vez, esta insistencia en la sombra colonial, expone la fragilidad de las jóvenes repúblicas, incluso de la paraguaya. Caído el poder aglutinante del imperio ¿cómo generar diferencias nacionales que justifiquen los límites territoriales? Alberdi no contesta esa pregunta pero su insistencia en el anacronismo colonial revela que, a pesar de las luces de Londres y París que alientan el imaginario de las élites rioplatenses, Sudamérica está lejos de haber sacudido completamente los lazos con la vieja metrópoli en decadencia, y el problema de la identidad nacional comienza a proyectarse sobre la arbitrariedad de los límites territoriales.

En este punto, Alberdi introduce en su discurso otro mapa "literal”. Esta vez, se trata de un objeto concreto y, como tal, tiene valor ejemplar: muestra la función conquistadora de la cartografía, seguramente ya antigua en el siglo xIx. Ganar territorio en los mapas preanuncia a veces la conquista real de los mismos. El mapa como objeto de intrigas y complots, objeto fetiche, casi mágico, que asegura la posesión de un territorio de otro modo inexistente. Simbolizar es poseer, y así como el siglo xix cierra el esfuerzo cartográfico iniciado con el "descubrimiento" de América, las nuevas potencias imperiales libran, en los mapas, batallas que jamás existieron en los mares. Denuncia Alberdi:

[...] desde 1678 existe un mapa, mandado construir oficialmente en Lisboa, en el que toda la costa atlántica, desde Río de Janeiro hasta el río de la Plata y todo el continente de la otra orilla hasta Tucumán, aparecen perteneciendo a la corona de Portugal (hoy el Brasil). Y nosotros conocemos un atlas publicado no ha mucho en Londres en el que todo el territorio brasileño aparece integrado con los territorios de la Banda Oriental, Entre Ríos, Corrientes y Paraguay. (80-81)

Brasil, el imperio fuera de lugar, borra y redibuja el mapa americano a la sombra rival del viejo imperio español. Así, un mapa del pasado puede transformarse en un mapa del futuro, batalla que se libra, obviamente, en el atlas del mayor imperio del momento, el británico. La guerra del Paraguay se transforma, entonces, en un juego de geografías, de estrategias de tablero, de "maquinaciones".

Pero Alberdi no denuncia el colonialismo como modo injusto de apropiación: tan sólo denuncia la ineptitud de Brasil para llevar a cabo tremenda empresa, reclamando que no cuenta con la superioridad (que sí tendría Europa) necesaria para hacerlo. En el fondo, su argumento se construye sobre el pasaje del modo colonial al modo imperial. "El mundo entero ha reemplazado a España en el goce de las ventajas del suelo americano y en el interés de conservarlo y defenderlo 
como beneficio propio y suyo” (36), advierte más adelante, donde se entrevé el pasaje de la lógica de dominación territorial a una economía ingenua de ventajas comparativas. Es la incorporación de Sudamérica al mapa productivo del mundo lo que preocupa a Alberdi, es su destino en tanto participante del sistema mundial lo que se juega en esta guerra. Se evidencia, entonces, a la guerra como parte de una maquinaria mayor, como la puesta en movimiento del mapa mundial, que decide la incorporación de territorios en función de la idea de Progreso. Acercar a las repúblicas del Plata al polo civilizado de la economía y la cultura, es decir, a Europa, es uno de los objetivos de estos ensayos. De ahí que, sobre los mapas antiguos de la colonia, Alberdi construya un cada vez más elusivo mapa simbólico. La función de este mapa simbólico será convertir la tierra misma en "zonas”, zonas pobladas por razas en concordancia o no con su suelo y con el ideal de Progreso del siglo.

Por mapa simbólico se entiende, entonces, el diseño global que arrojan estos textos: la constitución de sus polos civilizados y sus enclaves barbarizados; la división del mundo en zonas y razas; las metáforas que acercan simbólicamente territorios de otro modo separados por la distancia geográfica. Imaginar a América en Europa y a Europa en América fue para la élite americana la tarea de un siglo destinado a emular sus instituciones, a transplantar y traducir, operaciones que se revelan tanto en los textos fundacionales de los intelectuales criollos como en aquellos textos menores que documentan los viajes físicos de esta élite que describiera David Viñas ("La mirada a Europa”). Evidentemente, estas operaciones son, para Alberdi, un punto de partida para pensar la guerra. Pero, en estos textos, va más allá de ese imaginario basado en el "transplante" de instituciones. Su mapa supone la existencia de un diseño global, y a la vez, es teoría explicativa para la guerra en general. Su premisa es simple y resume la tesis del libro: "Si el tiempo es plata para las empresas de comercio, el espacio es oro y sangre para las expediciones de la guerra” (38). El mal americano -la extensión- identificado por Sarmiento en Facundo, civilización y barbarie y por el mismo Alberdi en Bases y puntos para la organización política de la República Argentina es ahora argumento estratégico que no sólo decide la guerra, sino que permite acabar con su discusión, colocando a Brasil fuera del mapa americano.

[Brasil] se toca por todos sus límites con todos los Estados de América del Sur, excepto Chile. A pesar de eso, el gobierno imperial dista de tal modo de sus grandes amigos [...] que el más inmediato de ellos (el del Estado Oriental del Uruguay) se halla a seis días de navegación por vapor de Río de Janeiro; el de la República Argentina, un poco más; el del Paraguay, como a catorce días, más de la distancia de Liverpool a Nueva York [...] Los gobiernos del Perú, del Ecuador, de Colombia, de Venezuela, están de Río de Janeiro a distancias más que transatlánticas. (38-39) 
Así, la distancia obra maravillas: la geografía se vuelve arma encendida contra lo foráneo, lo invasor. Las leguas, cuidadosamente medidas y transformadas en imágenes de ciudades, son las que expulsan a Brasil del mapa sudamericano. Si en las crónicas de la conquista, la naturaleza era obstáculo insoslayable para la marcha de la misión colonizadora-evangelizadora, en la versión alberdiana de esta guerra, la naturaleza ha desaparecido. No es la selva, la flora o la fauna lo que detiene el avance imperial: son las millas y las leguas; es la geografía en su más plana manifestación la que obra el encantamiento.

No son las fortalezas ni los cañones, ni las florestas ni las montañas, la principal defensa del Paraguay. Su baluarte más poderoso es el espacio de dos mil millas que las separa de Río de Janeiro. Ese es el foso en que se agotan los tesoros y los ejércitos del Brasil. (39)

Brasil, nos dice Alberdi, es tres veces extranjero en el territorio sudamericano: en raza, en idioma y en instituciones de "repugnante desigualdad", pues la esclavitud “y otras aberraciones coloniales” lo vuelven un anacronismo político (76). Pero, paradójicamente, su argumentación también coloca a Brasil demasiado cerca del polo civilizado, pues al concebir a Brasil como potencia imperialista, inmediatamente la compara con Francia. Comparación que no sólo aleja a Brasil sino que fetichiza la distancia. En efecto, Alberdi concibe a la empresa imperial como transatlántica, por eso recuerda que "la empresa lejana de México ha costado a la Francia un millón de francos” (39) . Colocar a Brasil en el mapa imperial implica sacarlo del mapa de América -presentar la Guerra del Paraguay como campaña extranjera- y a la vez acercarlo a la lógica europea, en suma: occidentalizarlo. Por eso, Alberdi se corrige y ensaya nuevas analogías. La comparación con Francia debe ser forzada y empujada hasta los extremos del mapa europeo. Brasil debe ser tan lejano a la América europeizada de sus Bases como a la Europa pro-americana que sueña el exiliado, de ahí que deba empujar la analogía hacia los límites, donde la lógica imperial deja de ser la lógica de la civilización. Con dedicación de cartógrafo, Alberdi ensaya un diseño tras otro hasta hallar finalmente la analogía que conviene en el extremo oriental de Europa: "Sería el imperio de Brasil engrandeciéndose con las repúblicas del Plata, como la Rusia con los despojos de la República polaca” (55).

En la misma operación, Paraguay se convierte en el paradigma de nación civilizada. Otra vez es el discurso geográfico, matizado por la "teoría del vacío americano" que Alberdi construyera en las Bases, el que informa este reacomodamiento del mapa sudamericano:

El Paraguay está situado entre desiertos argentinos y brasileros poblados de indios salvajes, formando un oasis de cultura entre la barbarie extraña que lo encierra, como sus ríos, geográficamente. (167) 
La imagen de Paraguay como oasis encerrado, inaccesible, baluarte de la civilización, tiene el efecto paradójico de representarla como tierra de excepción dentro del paisaje bárbaro de sus vecinos. Pero también juega a destituir -confirmándola, pero en clave positiva- la vieja metáfora con la que se conociera al país durante el gobierno del Dr. Francia: la China Americana. ${ }^{7}$ Burton mismo declara que uno de los propósitos de sus cartas es acabar con esa comparación que él, haciendo alarde de sus saberes de viajero experimentado en tierras orientales, considera ridícula (Letters... 1).

Pero Alberdi va más allá. Siguiendo esta idea de Paraguay como excepción civilizada, lo compara con Suiza por su territorio inexpugnable y lo considera heredero del "sueño dorado" de Bolívar de extender la revolución a Brasil (108). El mariscal Francisco Solano López, presidente de Paraguay, entra en esta argumentación de la mano de los héroes de la Independencia, y, lo que es más importante, también de los héroes extranjeros que llevaron Europa a América. Efecto metonímico del territorio y de los nombres que civiliza la cruzada paraguaya integrándola en una narrativa y un mapa mayores: ${ }^{8}$

El general López, nacido a un paso de Misiones, cuna de San Martín, y del suelo que lleva el nombre de Bolívar, es llamado a coronar la obra de esos grandes hombres en el suelo de Río Grande, abonado por la mano de Garibaldi. (108)

Alberdi dedica páginas enteras a enumerar las virtudes de Paraguay, que lo presentan como nación en lucha por entrar a la "familia de las naciones civilizadas". Su lucha es la de la civilización, pues es la de la libre navegación de los ríos, símbolo del Progreso y la apertura que lo alejan de la vieja metáfora de la China Americana. Además, cuenta con la primera fundición de Sudamérica; su población duplica la de la Confederación Argentina pero en un territorio mucho más pequeño; no tiene deudas con el extranjero; todos los soldados paraguayos saben leer y la mayoría escribir y contar. Concluye Alberdi "La Europa misma no tiene ejemplos de esta especie" (110).

7 La metáfora, acuñada en la época en que Francia - dictador de Paraguay entre 1816 y 1840- había cerrado el país al extranjero, es referencia casi obligada en las crónicas de esta guerra.

8 Dentro de este “mapa mayor” entran los esfuerzos argumentativos de Alberdi por mostrar la influencia de orden inverso:América determinando la historia europea. Argumentación que invierte el movimiento unilateral de la copia. Sería materia de otro trabajo analizar este esfuerzo de Alberdi, que sostiene, incluso, que el feminismo habría nacido en América: "La acción de América en Europa, empleada como elemento político por los partidos europeos, no es un hecho que recién esté por suceder. Ella se ha hecho sentir ya en la primera revolución francesa; en la reciente transformación de Italia, pues más de uno de los héroes ha creado en el nuevo mundo el prestigio que le ha servido en Europa; y hoy mismo en el movimiento feminista en Irlanda, cuya base está en América” (50). 
Pero hay más que estas analogías, que dibujan a Brasil cercano a Persia y a Paraguay al lado de Suiza. Detrás de ellas, alienta una antigua concepción geográfica a la que ya recurrieran los cronistas españoles de la conquista, ${ }^{9}$ aquella que supone al mundo dividido en zonas. Pasada por el tamiz hegeliano, la vieja tradición aristotélica encuentra en Alberdi la temprana matriz evolucionista que dará su color al siglo siguiente: del Espíritu que evoluciona a sus anchas en las zonas templadas a las naciones que se extinguen bajo el lema de "la supervivencia del más apto". Así, la guerra del Paraguay se enclava en esta racionalidad que divide al planeta de acuerdo a "misiones" geográficas. A cada nación su zona, a cada una su misión. Volviendo a Brasil, es tan notoria su mancha en el mapa americano que Alberdi lo coloca en el extremo opuesto, en las antípodas de las naciones americanas. "Brasil no tiene vecinos, tiene antípodas [...] No decimos la guerra; la simple amistad de sus vecinos es para el Brasil, como un cultivo de lujo" (38) declara desde el Prefacio, en el que, consecuentemente, acerca a Brasil a Francia o a Inglaterra en tanto potencia imperial en busca de espacio para sus colonos. Pero no exactamente. Pues no es el espacio lo que prima en esta guerra: es la lucha por el clima y no por el territorio la que determina las “maquinaciones” del Brasil:

El enemigo de Brasil no es el Paraguay, ni el Estado Oriental, ni el sistema republicano, ni el abolicionismo. Su enemigo capital es el sol de la zona tórrida. ¿Puede este enemigo ser vencido? ¿Es posible aclimatar al hombre de la Europa en el suelo de la zona tórrida? (58)

De acuerdo al diseño global de Alberdi, esta guerra de conquista no es más que el último intento desesperado de Brasil por sacudirse el yugo de la zona tórrida. No es territorio lo que le falta al país más extenso de Sudamérica sino "el clima que le falta al suelo propio” (57). Es que en la lógica alberdiana sólo la inmigración europea garantiza la llegada a la Civilización. De ahí, el expansionismo brasileño. $\mathrm{Al}$ anacronismo que significa la restauración monárquica en el suelo americano, Brasil suma el absurdo sincrónico de su raza. Doble inscripción de la monstruosidad brasileña del tiempo en el espacio: Brasil atrasa, tanto por su gobierno como por su suelo, condenado a ser habitable tan sólo por la raza africana, volviéndose inepto incluso para la copia de lo europeo. Después de todo, la idea ya estaba en Hegel. ${ }^{10}$

9 Ver, por ejemplo, la mención a la teoría de las antípodas y a la zona tórrida en Historia general de las Indias (López de Gómara, 1932).

10 En efecto, en Lecciones sobre la Filosofía de la Historia Universal, Hegel considera que sólo las zonas templadas son aptas para el desarrollo del Espíritu de la Historia: "Tiene, no obstante, influencia el clima, por cuanto que ni la zona cálida ni la fría son suelo abonado para la libertad de los hombres, para que en ellos puedan desarrollarse pueblos importantes en la Historia Universal [...] Así es, en general, la zona templada la que ha de ofrecer el teatro para el desarrollo de la Historia Universal y, dentro de ella, la parte septentrional es la más adecuada” (163-164, énfasis en el original). 
Se sabe, la semilla de la Ilustración y la Civilización sólo se desarrolla cómodamente en las repúblicas templadas. Subyace aquí, a pesar de Alberdi mismo, la vieja idea de Sudamérica como degeneración, América como copia de segundo orden o falsificación de la semilla de Occidente. Pero la percepción de Alberdi no llega a tanto, su argumentación se detiene en la monstruosa excepción brasileña:

Y como los Borbones de la mejor raza, que son los nacidos bajo el hermoso cielo de Francia, no irían a África para habitar países como el Madagascar, como Guinea, como Angola por su clima tórrido, en que acabarían por degenerar junto con sus súbditos de origen europeo, la consecuencia de la instalación soberana en el Brasil tendría que ser la reconstrucción del imperio con territorios templados habitables por los hombres de la Europa, condición que no puede realizarse sin suprimir más de una de las repúblicas del Plata, culpables de poseer los bellos territorios que el Brasil necesita para completarse, si ha de conservar el imperio con emperadores de raza europea. (48)

En esta misma línea, Alberdi busca separar a las Repúblicas del Plata del contacto con esa fuerza degenerativa que condena a Brasil. Sobre la cuadrícula hegeliana que dividía al mundo en zonas (la frígida y la tórrida condenadas a carecer de Pueblos sujetos de la Historia), Alberdi superpone la división norte-sur (también presente en Hegel, con la diferencia de que para el filósofo, el Sur estaba condenado al atraso). Pero, para Alberdi, las Repúblicas platinas pueden salvarse si despiertan a la "corriente civilizadora” del hemisferio Sur. Tal corriente atravesaría esas zonas como un hálito civilizador, un Espíritu nuevo, aquel que, lejos de la lógica hegeliana, no muere al contacto con lo tórrido o lo inmaduro. El Espíritu que vence en esa corriente al Sur del mundo acabaría con la diferencia brutal que desmembra al continente americano, es decir, acabaría con la diferencia entre Estados Unidos y Sudamérica, diferencia que el mismo Hegel percibía como extrema en cuanto al grado de desarrollo de sus sociedades: ${ }^{11}$

Como hay una América del Sud, hay también un Asia del Sud y un África del Sud. En la extremidad meridional de esos mundos florecen los colores sajones que han visto nacer a los Estados Unidos, y protegen hoy mismo, en el Sud como en el Norte, la aclimatación afortunada de la civilización y de la libertad sajonas, en Australia, Tasmania, Nueva Zelanda, Falkland y Buena Esperanza, formando alrededor del globo, esos planteles de civilización, una zona de libertad [...] en

\footnotetext{
${ }^{11}$ En palabras del propio Hegel: “En Norteamérica vemos una gran prosperidad, basada en el crecimiento de la industria y de la población, en el orden civil y en la libertad. Toda la federación constituye un solo Estado y tiene un centro político. En cambio las repúblicas sudamericanas se basan en el poder militar, su Historia es una continua revolución” (173).
} 
medio de la cual se encuentran colocadas las repúblicas de Sud América, que se imaginan no tener vecinos más poderosos que el Brasil. (61)

Los colores sajones o, más adelante, “el ideal de civilización británica” tienen el poder de trascender las taras de la geografía, de estirar los continentes y achicar los mares. Por arte de magia, Argentina y Uruguay se encuentran más cerca de Australia que de Brasil, pobre excepción de la naturaleza, inapto para atraer colonos blancos a su territorio tórrido, incapaz de despertar -por su geografía- a esa "corriente civilizadora”. Sin embargo, no todo está perdido para la nación brasileña. En el mapa móvil de Sudamérica que Alberdi acerca y aleja de Europa a voluntad, hay una misión, un destino geográfico y político para cada país.

\section{FETICHES TÉCNICOS}

En el mapa simbólico alberdiano la geografía cobra funciones mágicas: por un lado agranda las distancias entre las repúblicas del Plata y Brasil; por el otro, acerca a estas repúblicas a los mitos del progreso y la civilización europeos. Contabilizar la guerra en espacio implica hacerlo en tiempo. Espacio y tiempo, oro y plata, son las monedas que mueven el mapa del mundo finisecular. Los términos de espacio, que miden cercanías y lejanías, se traducen en Alberdi como metáforas de pertenencia a la pirámide evolutiva de las naciones. Esta mitificación del espacio-tiempo no se representa -como para la mirada del conquistador- a través del viejo mito de América como paraíso estático, en estado de disponibilidad, sino a través del frenesí que generan los inventos técnicos, que transforman la naturaleza y parecen aportar Progreso casi instantáneamente.

En la lógica alberdiana Comunicación equivale a Progreso, mientras que Aislamiento es igual a Atraso. Así, Brasil, por su geografía, participa de la cerrazón inadmisible del atraso o la barbarie:

Encerrado entre el Ecuador y el Trópico, el Brasil puede llamarse el África del nuevo mundo. Es peor que África, pues se daría de parabienes si tuviese territorios como el Delta, el Tell de Túnez y de Argel (...) que están arriba de 30 grados de latitud. Las grandes ciudades marítimas del Brasil ocupan situaciones análogas a las que África tiene en las ciudades de Zenegambia, Guinea, Congo, Angola, países que sólo pueden habitarse por razas de color. El blanco que allí no muere, vive muriendo. (72)

Siguiendo esta línea, sostiene que sus costas sólo pueden ser habitadas por africanos, mientras que sus regiones interiores son inaccesibles por falta de vías de comunicación (69). Brasil es un enclave de atraso, es la inversión de Paraguay, 
esa especie de ciudadela perdida, oasis del progreso. El territorio del Matto Grosso representa para Alberdi una apropiada sinécdoque del país: representa lo inaccesible, la cerrazón, el atraso. En esta idea de territorio inexpugnable, atrasado, Alberdi rescribe la idea de América como "continente misterioso", inexplorado. Vuelven, así, las viejas historias del trópico como una tierra encantada, cruel y caliente que, en la lógica alberdiana, sólo puede ser cultivada por africanos; las leyendas de fiebres y enfermedades misteriosas, noticias de blancos que mueren al primer contacto con la atmósfera de la selva, en fin, lo que Alberdi, en un repaso rápido y arbitrario por el pasado de las colonias portuguesas, llama "la lúgubre historia de la colonización en Brasil” (73).

En suma, por su anomalía geográfica, Brasil es inepto para el lema del siglo: “Gobernar es poblar”. Detrás de esta premisa que embandera la programática alberdiana para la República Argentina subyace la ecuación Progreso=Comunicación. Por lo pronto incluye tanto a los barcos (pues el poblar implica la inmigración europea) como a las personas, en este tránsito/tráfico, en esta fetichización de la circulación que parece garantizar la civilización instantánea para las nuevas repúblicas.

Por eso, en el otro extremo de la argumentación, Paraguay ocupa el polo civilizado, porque, según Alberdi, pelea por la librenavegación de los ríos. El mariscal Francisco Solano López ha abierto las fronteras que sus antecesores mantuvieran clausuradas y eso garantiza -según parece- la libertad que trae el progreso. O el progreso que trae la libertad. Necesariamente, la cualidad de "inexpugnable", cambia ahora de signo: "Con sólo abrir sus puertas de par en par a la entrada del mundo civilizado, esas repúblicas se convierten en paradojas inexpugnables para los conquistadores atrasados" (38).

Así, la identificación entre Paraguay y China ha quedado en el pasado, pues ahora éste pelea por volverse fortaleza a fuerza de comercio, de comunicación. Y la comunicación -a esta altura del siglo-son los mares y ríos. Se trata de una inversión poética del espacio marino: si para la tripulación de Colón era el territorio poblado de monstruos, para el imaginario moderno es aquél poblado de maravillas técnicas que operan la magia del Progreso. Contacto, vecindad, comercio son las divisas del momento. Entre otros muchos ejemplos, señala Alberdi: "El mar que se interpone entre América y Europa no impide a los Estados Unidos vivir en sociedad de los grandes poderes europeos; es, al contrario, el mar el que les da vecindad” (34). ${ }^{12}$

\footnotetext{
${ }^{12}$ En un texto posterior, El crimen de la guerra, Alberdi amplía esta concepción “moderna”, hiperbólica del mar: "Dividido por el mar-decían los antiguos porque no eran navegantes-Unido por el mar -es locución de los modernos, porque el mar es un puente-que une sus orillas, para pueblos navegantes, como los modernos [...] El vapor no sólo ha suprimido la tierra como espacio, sino el mar. Como el pájaro, el hombre se ha emancipado de la tierra y del agua, para cruzar el espacio casi en alas del aire” (131, énfasis en el original).
} 
Pero no sólo los mares actúan esta magia. También las invenciones técnicas que los acortan. Abrir la puerta a las corrientes del siglo (metáfora también fluvial) significa también abandonar viejas máquinas y adoptar nuevas. Aquí el imaginario técnico de Alberdi demuestra su consonancia con el siglo siguiente: el de las estadísticas, el de los proyectos fuera de la escala nacional o globales, el de la racionalización técnica que desembocará en la Primera Guerra Mundial.

Orden y Progreso van de la mano de estas máquinas, que no son solamente máquinas de producción. Más y primeramente, en esta programática alberdiana, importan las máquinas políticas. Primero, las máquinas de gobierno: abandonar las raíces obsoletas de la colonia (y sus múltiples divisiones internas) y adoptar, de acuerdo a la "ley natural”, la centralización, verdadero Estado civilizado “que es una máquina aritmética, por la cual el valor de un hombre se multiplica por tantos hombres como el país contiene” (32). Segundo, las máquinas de producción, fetiches al alcance de todas las naciones que garantizan el triunfo sobre la naturaleza, incluso en aquellas zonas donde el Espíritu de la Historia languidece. Las máquinas de producción coloniales deben suplantarse por las máquinas capitalistas, que de la mano del "ingenio" trascienden las determinaciones geográficas. Con la entrada de las máquinas, los dos mapas (el de la Colonia y el que divide al mundo según las gradaciones geográficas del Progreso) vuelven a superponerse:

Hay un emperador más poderoso que Carlos V [...] para él no hay zona tórrida ni zona glacial; no hay polos, no hay antípodas. Ese poder es el genio industrial del hombre de este siglo [...] desde que el calor, el hielo, el vapor, el aire, la electricidad, el gas, el agua, vencidos y sometidos a su dominación, han venido a ser los nobles esclavos del hombre. (59)

En esta línea, Brasil, condenado por su geografía, encuentra su redención en la imaginación técnica. No hace falta más que suplantar la maquinaria de guerra por la maquinaria de producción. Declara Alberdi que el primer triunfo sobre la barbarie fue hacer del hombre una máquina de agricultura. En esta segunda etapa, la tarea es hacer de una máquina "un esclavo que trabaja, que transporta [...] que ataca, que alumbra, que releva al negro esclavo de su cruel destino, en el hogar, en los campos, en las minas, en la guerra, es el triunfo espléndido de la civilización sobre la materia, triunfo sin sangre, ni víctimas, ni lágrimas” (59).

Claro que la sangre, las víctimas y las lágrimas hacen referencia no sólo a la esclavitud -síntoma por excelencia de la monstruosidad brasileña- sino también a la guerra misma. Allí es donde Alberdi pasa de las maquinaciones a las máquinas, donde la geografía se articula finalmente con la raza y ambas con la guerra como instrumento ineficiente. La guerra, en última instancia, ha de reemplazarse por otro tipo de máquina, una máquina racial. Sea que la presente como el complot 
brasileño hacia una imposible "Unión Ibérica” (hipótesis que Alberdi contempla por un momento pero descarta porque América del Sur, a diferencia de la Península Ibérica, no contaría con las "necesidades imperiosas de la geografía” para que tal unión fuera necesaria), sea que la presente como un plan de exterminio, la guerra pasa de conflicto geográfico territorial a lucha racial sin solución de continuidad:

No son territorios únicamente lo que el Brasil intenta desmembrar, son nacionalidades, razas, familias, lo que el Brasil, portugués de origen, aspira a desmembrar en el Plata, poblado de gentes de origen español. Tal aspiración es la guerra sin fin; y tal guerra es el exterminio del pueblo que se quiere heredar. (125)

Es cierto, estos ensayos de Alberdi claman por la intervención europea y argentina en una contienda que recién comienza. Como tal, el reclamo cobra forma predictiva: más del setenta por ciento de la población paraguaya morirá en esta guerra de exterminio. De modo que la guerra no está lejos de ser el genocidio que Alberdi plantea con tanta lucidez (aunque las Repúblicas del Plata elegirán el bando de acuerdo a otras posiciones simbólicas, no con atención a la supuesta hermandad que garantiza la común sangre española). Pero la máquina racial funciona en otro sentido. Es la solución de Alberdi a la "monstruosidad" de Brasil: otorgarle una misión domesticadora de su propio territorio, una misión que, de la mano de la imaginación técnica, respete la unión inexorable entre raza y geografía. Brasil, liberado al fin de su excepcionalidad tanto geográfica como política, gracias a las máquinas, abdicaría de su voluntad expansiva que busca un clima apto para su necesaria modernización, si y sólo si aceptara una última ecuación de la máxima Progreso=Comunicación: la de la purificación de la sangre. La máquina racial es el último paso de la fetichización de la circulación que supone esa premisa. Y esa premisa es la única que garantizaría la paz. Como no podía ser de otro modo, con la paz, Alberdi encuentra el camino para la confluencia entre técnica y religión. La armonía de Sudamérica implica culminar la tarea mesiánica, reencontrar, en la ciencia y en la técnica, el camino hacia Jesucristo:

La paz exige dejar a cada clima su raza histórica y normal. Acepte Brasil la noble y caritativa misión que le da la zona tórrida de emblanquecer por el cruzamiento la raza negra, esclavizada para sus comodidades. Son dos razas que se sacrifican una a otra para redimir la parte del género humano que es la excepción afligente de nuestra especie. El clima espléndido del Trópico es el eterno Edén en que se opera el renacimiento de una mitad del género humano hacia los nobles destinos trazados por la religión de Jesucristo. (127) 
Sólo así la excepción brasileña colabora con la reescritura en América del Paraíso original. En su elusivo mapa del mundo, Alberdi realiza la síntesis imposible entre ciencia y cristianismo, dos pilares herederos de la misión de la colonia. En el siglo de Spencer, Dios actúa por mano de los mandatos sagrados del Progreso, aún cuando ellos se encarnen en la comunicación de las sangres. Última confirmación de la Filosofía de la Historia hegeliana, la Sudamérica de fin de siglo parece triunfar, en la diatriba alberdiana, sobre su propia excepcionalidad. La geografía, antes obstáculo insoslayable y símbolo de inmadurez, redefine su papel en este mapa redibujado hasta el cansancio: no es condición, no es origen, es destino.

En el final, la magia geográfica se ha consumado: América vuelve a ser el Paraíso terrenal que fuera en sus orígenes, siempre y cuando cada nación acepte el destino divino que le ha sido otorgado. En este sentido, la geografía no es obstáculo a vencer, es misión milenarista transformada en tarea política y moral. Para mayor claridad, así concluye Alberdi este pasaje: "La geografía no es un simple hecho de orden físico; por su influencia sobre el hombre, es también un hecho de orden histórico y moral” (127).

\section{BIBLIOGRAFÍA}

Alberdi, Juan Bautista. El crimen de la guerra. Buenos Aires: AZ Editora, 1994. La Guerra de Paraguay. Asunción: Intercontinental Editora, 2001.

Burton, Richard F. Letters from the Battle-fields of Paraguay. Londres: Adamant Media Corporation, 2005.

Hartshorne, Richard. The Nature of Geography. A Critical Survey of Current

Thought in the Light of the Past. Lancaster: The Science Press Printing Company, 1949.

Hegel, Georg Wilhem Friedrich. Lecciones sobre la Filosofía de la Historia Universal. Madrid: Ediciones de la Revista de Occidente, 1974.

Humboldt, Alexander von. Ensayo político sobre el Reino de la Nueva España. México: Porrúa, 1991.

Lopez de Gómara, Francisco. Historia general de Indias. Madrid: Espasa-Calpe, 1932.

Lund, Joshua y Malcom McNee, eds. Gilberto Freyree os estudos latino-americanos.

Pittsburgh: Instituto Internacional de Literatura Iberoamericana, 2006.

Montaldo, Graciela. Ficciones culturales y fábulas de identidad en América Latina. Rosario: Beatriz Viterbo, 1999.

Pratt, Mary Louise. Imperial Eyes. Nueva York: Routledge, 2003. 
Thompson, George. The War in Paraguay. With a Historical Sketch of its Country and its People and Notes upon the Military Engineering of the War. Londres: Longmans, 1869.

Viñas, David. "La mirada a Europa: del viaje colonial al viaje estético”. Literatura argentina y sociedad. Buenos Aires: Centro Editor de América Latina, 1982. 
1 